\section{Alain Degenne and Yannick Lemel: Sociologie des comportements intentionnels}

\author{
Paris: Economica, 2006. 422 pp.
}

There is a dearth of textbooks leading up to the style of sociology exemplified by, among others, the European Sociological Review: a clever problem choice, systematic theorizing, and rigorous testing. American textbooks present sociology as a grab bag of topics, the theories in British treatises are so liquid that students may wish for a bar of soap, and German tomes are so concerned with the conditions for the possibility of sociology that sociology's research findings take the back seat. The French book under review fills this gap to a large extent. If more of its examples had been taken from English publications, a translation into that language might have been a hit.

The book aims to provide a tool box for those who wish to analyze individual behavior from a sociological perspective, and does so by starting from the assumption that individuals act with a minimum of intentions (a synonym for purposes). It distances itself from narrowly conceived rational choice explanations, and dissects as well as synthesizes a large number of highlights from half a century of sociological studies. The examples include field work in developing countries, archival research, and network mapping. To achieve their aim of synthesis, the authors disavow the holistic concept of culture and define culture as shared beliefs, so that analytical exercises at the macro-, meso-, and micro-levels become possible by specifying who does the sharing. The first part of the book (Chapters 1-4) is an introduction and shows, by way of examples, that three types of explanations are involved in the analysis of specific cases. The fourth part (Chapters 12-15) sums up. The second part (Chapters 5-8) views 'cultures and representations as sciences and collective norms', the third one (Chapters 9-11) takes 'the relational environment as context and construction'. Behind these vague titles lurks one big substantive statement, consisting of three layers providing better and better approximations. This reviewer articulated them as the following falsifiable propositions:

(a) the actions of persons are adequate to the intentions they have (this is close to what the authors in Chapter 4 call the under-socialized view of persons in rational choice theories),

(b) the actions of persons square with the shared beliefs of the groups they belonged to when young and conform to the norms of these groups (what the authors call in Chapter 4 the over-socialized view of 1950s sociology textbooks),

(c) persons are more likely to take a new course of action if that action already was performed by an individual who belongs to their networks, who has a higher status and who has more outside links, and if that network contains more holes (this proposition apparently is the middle ground sought by the authors between theories of under- and over-socialization).

These propositions are prompted by three series of instructive examples. One series involves the diffusion of a new type of maize among farmers, the prescription of a new drug by physicians, and the buying of new clothes by women (Chapter 1). The second one pertains to two persons locked up separately by a sheriff who suspects them of having robbed the mailcoach together (Chapter 2). The third one invokes cases of altruism, more precisely giving and receiving various kinds of help between parents and their grownup children in contemporary France, as well as bread, circuses and public buildings offered by wealthy Roman citizens to their town (Chapter 3). Chapter 2 would have been more interesting for students if the prisoners' dilemma, usually taken as a two-person game, had been turned into a three-person game, in which the sheriff always wins and order in society gets restored.

The second part of the book, after defining culture as shared beliefs (Chapter 5), misses out on research findings on group climate effects, as for instance reported by Barton in the 1968 American Behavioral Scientist. These results corroborate the (obvious) hypothesis that a person's actions are not only in line with this person's previous actions, but also live up to the norms of this person's environment. They carry forth the Lazarsfeld-inspired series of examples from Chapter 1 about the diffusion of innovation, and avoid the problem that the phenomenon to be explained and the phenomenon doing the explanation both pertain to behavior, so that circularity might occur (the authors warn against this danger of oversocialization explanations on p. 146).

Chapter 6 turns into a useful list of instruments for ascertaining the networks to which persons belong (for instance: ask names of friends and ask whether they know one another) and Chapter 7 into an equally useful list of measurements for shared beliefs (resulting in a ranking of countries after the percent of the population with religious and postreligious values). 
Chapter 8 posits that there always are several contexts and several cultures, and more or less leaves it at that. The old Lazarsfeld hypothesis that cross-pressure makes for nonvoting would have made a worthwhile case, as well as the diagonal reference models presented by Sobel in the 1981 American Sociological Review. These models estimate the effect on the actions of socially mobile persons of norms that differ between origin and destination groups.

The third part of the book discusses a long quote from Simmel (Chapter 9), but for some reason or other avoids the related and more specific 1984 Blau and Schwartz hypotheses on the effects of group size, heterogeneity, inequality, and cross-cutting social circles on who marries whom. Chapter 10 is most interesting. It deals with the topic of how persons influence their microenvironment (rather than the other way around): persons who invest in a network with holes climb up faster in their work organization, people marry persons with characteristics like they themselves have, and now that jobs make women financially independent women divorce more frequently.

The authors point out in Chapter 11 that markets never are completely free by bringing in the idea of trust. In this reviewer's opinion, it is not necessary to bring in the notion of trust. The present reviewer convinced himself that buyers are not independent and act as group members, by noting that a lot of people buy a pine tree in December only and that other people never eat pork. The authors also point out that some persons at one and the same time belong to several organizations, with the norms of one organization (say, a political party) being inconsistent with those of another (say, a church). Given these observations on markets and organizations, it is unfortunate that the authors speak throughout about rational choice theories. The application of these theories in the field of religion made clear that the rationality assumption is not that crucial, pivotal is that this assumption is applied under the condition of the existence of competitive markets. The tag 'market theory' provides a nice contrast to the over-socialization hypothesis that organizational norms are always strictly followed, and by this opposition it would have become quite clear that networks are a middle ground. This is the main theoretical contribution of this book, which aims for synthesis.

In Chapter 12 of the final part of the book, the authors return to their definition of purposive action by maintaining that actions differ in the time elapsed before they attain their intended results. Most human actions have a short-term intention. To this reviewer, this misjudges the place of religion in society, since religions are far from dead and aim for individual effects after death. Following the authors' idea of a well-filled tool box, the authors maintain (Chapter 13) that ego had three types of intentions: respect of values, access to social goods, and the wish to belong to a group and to attain a higher status within it. They also list three social goods: money, prestige, and power. The authors are faintly aware that nowadays this Weberian view of stratification has been replaced by Neoweberianism, which holds that classes, parties, and status groups are phenomena of a society's power relations, and that power relations determine a person's life chances.

The authors also discuss the question of why people sometimes break rules (Chapter 14). This chapter looks out of place, it should have been included in the third part of the book. Also, their discussion of Merton's 1938 propositions on anomie as a societal characteristic making for various modes of individual adaptation, should have been preceded by a discussion of Hirschi's 1968 attachment theory of juvenile delinquency.

The authors finally list resources (Chapter 15): human capital, cultural capital, economic capital, and three types of social capital. One type has meaning on the microlevel, another on the mesolevel, and yet another one on the macrolevel. The first one stands for the 1967 Beatles hypothesis that people get by with a little help from their friends, and the second one for the 1995 Burt hypothesis that people's career prospers more if their friends do not know each other. To this reviewer, the hypothesis associated with the third type remains unclear (just like Putnam's Bowling alone from 2000 is ambiguous: if everybody plays bowling as a member of a club, it still may be the case that blacks and whites are bowling apart). This hypothesis might be something like the following proposition, which held for the Netherlands in the 1950s: in a society with inhabitants who belong to different churches or other mass organizations, who have hole-free social networks, but networks that do not tie into each other, governments take more time to form after elections and they more likely fall before their term is up.

It is a pity that the authors in Chapter 15 belittle the distinction between resources and constraints. In this reviewer's opinion, sociologists too often assume that people cannot have less than zero resources. (In Resources for social change from 1971 Coleman followed Olson and pinpointed negative resources.) However, it is obvious that negative resources (nescience rather than science, monetary debts rather than wealth, foes rather than friends, and illegitimate 
rather than legitimate leisure life styles) are possible. And the investigation of these topics might yield more than that of familiar ones: do people take on a job that pays less if their boss is too bossy (for an example, see Moerbeek and Need in the 2003 Social Networks), do children of parents who do not go to classical but to pop concerts, do worse in school than children whose parents do not visit concerts of either type?

For all these reasons the authors' attempt at synthesis does not fully succeed. Their cases always are interesting, the examples do result into an array of theories, but the authors miss several opportunities to fill sociology's toolbox to the brim. The prime reason for this seems to be that the book wastes space on making definitions and the comparison of definitions, whereas those pages should have been used for outing propositions. There are many more falsifiable propositions around than commonly assumed, and they should be presented in textbooks.

The other reason is as follows. Boudon once admitted that sociology is concerned with many different topics, and the authors apparently think so too. In this reviewer's opinion, this is plain wrong. Sociology's big questions pertain to societies, to wit their cohesion, the inequalities between their members, and the speed of rationalization processes. And for those who do not like this return to sociology's founders, there is another way of giving sociology's topics more coherence, particularly when sociology is held to study purposive individual action, as is done in the book under review. After all, sociology's questions often involve the unintended consequences of individual action. A synthesis in sociology also comprises the creation of order in the chaos of its topics.

\section{Wout Ultee \\ Radboud University Nijmegen \\ W.Ultee@maw.ru.nl}

DOI:10.1093/esr/jen066, available online at www.esr. oxfordjournals.org

Online publication 5 December 2008 